\title{
From Vision to Reality: The Evolution of a Library Model
}

\author{
EVELYN WOODBERRY and JOANNA RICHARDSON ${ }^{i}$
}

\begin{abstract}
This paper discusses the way in which the establishment of an academic library has been managed at a new university in the 'information age'. Bond University, Gold Coast, Queensland was established in 1987 as the first private university in Australia. In its tenyear history the university has suffered mixed fortunes which have been reflected in the development of the library.

The paper investigates the model proposed to support the vision of an electronic library in the late 1980s, and the issues associated with its implementation in an environment of emerging technologies. It outlines the impact of the model in shaping the future development of the library, and how it was altered to accommodate the available technologies and to meet the changing circumstances of the university. The paper does not focus on the personalities and controversy surrounding the proposed model.
\end{abstract}

Located on the Gold Coast in Queensland, one of the fastest growing urban regions in Australia, Bond University commenced undergraduate teaching in May 1989, having been established by an Act of the Queensland Parliament in 1987. The university was a joint venture between an Australian company, Bond Corporation, and a Japanese corporation, EIE International Group.

The vision was to integrate research with the practical application of acquired skills so as to equip students with the challenges of an increasingly competitive international environment. In the words of the University's namesake, Alan Bond:

The establishment of Bond University will herald innovation. It will be open to individuals, groups, companies and government agencies to pursue cooperative activity on campus. It will be a practical university, utilising the latest techniques in management and communications. It will enable students to carry out high technology studies in conjunction with private enterprise in the university's research park. ${ }^{1}$

If Australia was to become an economic player in the Asia-Pacific region, then Bond University was to provide graduates capable of contributing to the economic growth of those nations.

The faculties of the University were initially the School of Business and Law, School of Humanities and Social Sciences, School of Information and Computing Science, and the Graduate School of Science and Technology. Later these evolved into the School of Business, School of Law, School of Humanities and Social Sciences, and the School of Information Technology.

\footnotetext{
' Evelyn Woodberry is Director of Information Resources, Bond University, Gold Coast QId 4229. Email: eve_woodberry@bond.edu.au Dr Joanna Richardson is Associate Librarian at Bond University, Gold Coast Qld 4229. Email: joanna_richardson@bond.edu.au
} 
The Bond University Library, designed by the internationally acclaimed architect Arata Isozaki, forms one wing of the distinctive, arched building in the central campus. The branch library for Law is housed separately on levels two and three of the Law School building.

[photo: http://epublications.bond.edu.au/people/16/]

Left to right: Marian Fletcher, Subject Specialist, School of Information and Computing Science; Evelyn Woodbury, Fastech Coordinator; Joanna Richardson, Information Technology Librarian; Sandra Jeffries, Subject Specialist, School of Humanities and Social Sciences; and Pam Clements, Subject Specialist, School of Business

The University Library was established in 1988 under the guidance of Cathy Tweedie, inaugural Library Manager. This was prior to the opening of the university and offered a window of opportunity involving the establishment of a totally new university with a strong commitment to using information technology in teaching, research and the provision of information and without the impediments that exist in established institutions. ${ }^{2}$

The model for information services adopted by Bond was based on Patricia Battin's vision of the electronic library, ${ }^{3}$ and is a structure which has been adopted in a number of institutions throughout the 1990s. In the publication Strategic Planning for Computing, Information and Technology at Bond University (commonly known as 'the blue book'), Dr Edwin Brownrigg, Director of the Office of Computing and Information Technology, provided the vision of a centralised and coordinated information and technology management division, which included the library, computing services, communications, audiovisual services and educational technology under a chief information officer. ${ }^{4}$ Bond was well ahead of its time when it established this structure; unfortunately, for reasons which this paper will not be covering, the structure had reverted to that of a traditional university by the mid1990s.

\section{DUiE: The Model}

The traditional solution to the problem of creating a library for a new university was to acquire as much paper and print as the start-up budget could afford. The traditional approach was not a feasible solution for Bond, especially given the University's desire to establish international recognition with a strong emphasis on scholarship. Therefore the focus was on designing a new type of electronic access and document delivery system for an academic research library. The US consultants hired specifically to design such a system were a group known as Infour (Brett Butler and Martha West); they named their prototype system DUiE-the Information Utility. 'DUiE' was, as one might guess, a phonetic homage to Melvil Dewey.

Infour looked at the then convergence of the development of mass storage devices and high speed, large bandwidth LANs with the standardisation of data delivery, particularly ASCII text and bit-mapped images. Their goal was to create what they called 'electronic libraries', based on the use of mass-storage image handling, specifically archival optical storage media. ${ }^{5}$ These optical jukeboxes would be used to store bit-mapped images of selected print materials, which would constitute the core of 'valuable research resources'.

A number of international projects involving the development of electronic document systems spurred Infour on to pursue this approach. Key projects included ADONIS, Project Mercury and the Quartet project. The US consultants admitted that the amount of storage required to handle image-based systems was a major 
drawback, but they projected that the increase in storage capacity coupled with rapidly reducing storage costs would make optical jukeboxes an attractive solution. In the interim, Infour planned to use commercially available WORM drives as their starting point.

Along with the concept of 'optical image archival storage' went that of a demand-based collection approach, which was designed to address the key question, 'What do we actually store?' Drawing upon all the known data about information use, the consultants concluded that they would selectively convert higher use materials, i.e. 'works of proven high use or value'. Moving away from the model of preoccupation with an entire journal, they estimated a conversion between 10-20\% of articles appearing in a ten-year run of any given scholarly journal. (Once again we note the emphasis on 'scholarly'.) The end result would be the development of 'real electronic libraries-integrated databases providing collections themselves as electronic images'. ${ }^{6}$ Fortuitously Bond University was to provide Infour with the opportunity to develop an actual working model of such a library.

The copyright issues associated with the selection, storage and re-use of material receive only brief mention in the original documents. However, Goodram and Butler acknowledged in 1990 that the most frequently asked question was how would they deal with the copyright problems associated with the electronic conversion and distribution of printed works. ${ }^{7}$ Their response was that copyright issues could be successfully addressed through direct site licences and usage agreements. It was intended to use existing US organisations to obtain clearance where possible and engage in direct discussion with copyright owners where necessary. The copyright regulations which framed the approach of Infour are the same today. However, although site licences for the use of electronic materials have become the norm, libraries which have taken the option of direct negotiation have discovered that it is a time consuming task with a limited success rate.

Traditional interlibrary loans at the time was deemed to be too slow and so the consultants envisaged the creation of what they called 'virtual libraries': remote resource agreements with organisations housing very large collections. Their example was USBE (United States Book Exchange), the world's largest duplicate exchange cooperative service. The idea was that these organisations would have on site the necessary hardware and software to convert print documents to electronic format and then transmit the results to the requesting institution, e.g. Bond University Library. The description of this process strongly resembles the Ariel workstation.

However, the major difference with Infour's model was that documents transmitted electronically to Bond would be stored and indexed so as to be delivered locally to the next user who might request those same documents. The concept would be similar to using Ariel to transmit and receive a document, which would then be written off to a drive that would then be indexed. The document would be accessible by all patrons in the same way in which one could deliver Social Science OnDisk (SSO) across a network. The only difference from SSO would be that the CDROMs would have contained articles requested by patrons rather than complete runs of journals.

Despite such a heavy emphasis on 'documents', Infour did not believe that electronic library collections would replace what they called the 'Core Collections', i.e. print materials, in the foreseeable future. ${ }^{8}$ For this type of material, they wished better to serve the patron by offering electronic browsing, without having to go to the stacks. As part of the DUiE utility, the Book Image Project encompassed scanning into electronic document form approximately ten 'browsing pages' from complex scholarly 
and reference works: title page, table of contents and index. These would be stored online, allowing any search of the book's cataloguing to be expanded instantly to a page-image display at the user's workstation.

According to the model, Bond University was to import the University of California Melvyl public search system for support of database searching: large-scale literature, index, abstract, and bibliographic. It was to function in the broadest sense of the word OPAC. While Melvyl was to handle information retrieval and access, Massachusetts Institute of Technology's Project Athena was to handle campuswide but private information processing needs: electronic mail, word processing, password authentication (Kerberos), and the like.

Well, that was the model in theory. Needless to say, these proposals received a mixed reception from the Australian library community. The plan to service the information needs of the Bond community by means of Californian university libraries, i.e. Melvyl, was controversial to say the least. Reactions to this and other proposed initiatives ranged from downright disbelief to outright envy.

The fundamental problem with the DUiE prototype was that a lot of what was being proposed was leading-edge technology based on discrete, betastage projects. The key element needed to bind these all together into a unified system for Bond University was lacking: that element was time. More time was required to adapt what were essentially American solutions-some of which were nothing more than vague proposals-to the Australian context and then to link all the bits and pieces together into an actual working model.

\section{Technological Infrastructure}

In terms of technological infrastructure, Bond University had an enormous advantage over older institutions: it did not have to adapt modern technologies to antiquated building structures. ${ }^{9}$ Instead the university had the good fortune to have its network installed at the same time as all the buildings were being erected. Large tunnels were constructed between sites to accommodate communication wiring; as buildings were erected, communication risers were installed to every floor and data outlets were provided in every room.

The adoption of TCP/IP communications protocol as well as the principle of open systems clearly focused on the importance of the network. Thus from the very beginning all staff-academic and general-had ready access to all the major information resources of the University: academic computing, computer-assisted learning, administrative and library databases, a distributed email system, and access to external networks and databases. Staff were given a choice of either an IBM PS/2 60 or a Mac SE on their desktop. In short this infrastructure was designed to support the model elaborated by Infour.

\section{Establishing Technical Services}

While the vision of DUiE and the 'blue book' provided strategic direction for the library, the reality of providing resources for students on 'day one' (May 1989) meant that it was necessary to purchase and provide access to information. This required the establishment of systems to manage acquisitions, cataloguing and serials to support the core collections mentioned above. Strategic decisions made at the beginning of the process were to use technology wherever possible and minimise manual processes, and limit retrospective collecting of serials to subject areas where this was required for accreditation purposes. ${ }^{10}$ In setting up these systems, there existed the opportunity to select the most appropriate technologies to maximise the efficiency of these functions. However, it was also important that in the immediate 
necessity to purchase these systems we did not lock the university into choices which would pre-empt the strategic planning process and the use of developing technologies.

The opportunity to automate as much as possible the acquisition and processing of material was considered essential based on the short time frame available and the prospect of limited staff resources. In response to this it was decided to implement a 'total quality management' approach to the ordering process. The use of a computerised acquisitions system would be able to provide the data required to measure the various parameters associated with the ordering process, e.g. supply times, percentage of orders filled, and consequently the decision was made to use a microcomputer system for this process. At this time bibliographic tools such as Books in Print and Bibliofile were becoming available on CD-ROM providing a mechanism for bibliographic checking integrated with the ordering system. Also in its infancy were online access to stock databases and electronic ordering with several of the major book and serial suppliers.

While the use of the technology offered some benefits in speed of delivery and improvements in selected processes, there were challenges in the use of dial-up access and the instability of the power supply on the Gold Coast. These processes have vastly improved in the intervening years with the introduction of the Internet and increasingly sophisticated systems used by both libraries and suppliers to a situation where in the late 1990s this had become the normal process for ordering in most institutions.

The timing of the establishment of the library (1988-89) was a few years too early to take advantage of the availability of the electronic full-text serials either as ejournals or as databases, and consequently it was necessary to undertake the management of a print serials collection. Again a microcomputer-based system presented the only practical solution.

In the method of serials management Bond took the opportunity to utilise the services offered by the library's suppliers to minimise in-house processing requirements. ${ }^{11}$ All overseas subscriptions were placed with Swets Subscriptions Services using their consolidation service. At this point in time the service involved the delivery of serial parts to Swets where a system of check-in and claiming occurred prior to the issues being packed and airfreighted to the library. This service minimised the in-house administration requirements, and limited the trauma of changing address three times in as many months. This service has been refined and re-evaluated over the years and still provides the value which attracted Bond over ten years ago.

The challenge for the library in setting up cataloguing was to find as quickly as possible the most cost-effective method to obtain machine-readable records, for the highest possible number of bibliographic items. Bond's response to this issue was to negotiate with suppliers for the provision of fully processed items: stamped, tattletaped, labelled, date due stamps inserted and LC MARC records on disc or tape for loading into the library system. When it was necessary to obtain materials from other suppliers Bond used Bibliofile and ABN (Australian Bibliographic Network). Bond became a member of $A B N$ in 1988, and as the library became established and the urgency of acquiring large quantities of material in a limited period settled into a more structured purchasing pattern, the use of $A B N$ (and later Kinetica) for obtaining records became the preferred option. 
In the late 1980's Bond was a pioneer in Australia in the use of suppliers to extend the services they provided. In the years since a number of institutions have taken this model and extended and expanded it, building relationships with suppliers to the mutual benefit of the industry.

\section{Reality Bites}

As the University was preparing to open, the whole financial infrastructure provided by EIE and Bond Corporation was collapsing in the background. ${ }^{12}$ So while the Library's technical services as described above were fortunate enough to be established along lines which proved to be effective in both the short and long term, other library services did not fare so well. included:

Major impacts of the university's financial challenges upon the library

- Termination of contractual arrangements with Dr Brownrigg, Infour and other US consultants

- Lack of capital to fund the DUiE prototype

- Closure of the Graduate School of Science and Technology

- Staff cuts in November 1991 (later mirrored by other institutions).

The end result was an obvious gap between the 'vision'-as envisaged by the DUiE model-and the information service strategies which were actually implemented. If the Infour team faced enormous challenges in translating their ideas into a model, the library staff faced equal challenges in having to revise totally that model - in an extraordinarily short timeframe-so as to be able to offer 'normal' library services on Opening Day. The failure of the US consultants to deliver a functional technological model forced the library to re-think its whole service program. The deconstruction of literary models may have been fashionable at one time but the deconstruction of library models was fraught with stress.

\section{[photo]}

The collection being moved into the library: May 1989

\section{Implementation of Services}

When the University opened for teaching in May 1989, it had been one of the wettest summers for many years. This caused delays in the building program, and the new library building was not available for occupation before the start of teaching on 15 May 1989. The grounds were reminiscent of a swamp, and telephone conversations were interrupted by the sound of drilling as workmen attached the sandstone to the external walls. Staff came to work in gumboots and ploughed their way through mud into not quite finished buildings. The atmosphere created by staff and students, however, was buoyant in recognition of the start of a new era in higher education.

As soon as access to the building was permitted, collections began to be moved onto the shelves from storage, and service points and systems set up. An extraordinary effort by all concerned ensured that the library opened for business on Monday 22 May. Staff moved into office areas as they were completed over a period of several weeks; senior subject librarians had to wait several months for suitable accommodation in the new building. In October 1989 it was decided to convert the second floor of the Law School building into a separate law library. This was completed a year later.

In providing a reference collection and service, the policy was to provide electronic access to reference sources wherever possible. Since the university ran TCP/IP without any other LAN software, all the CD-ROM databases had to be run in 
stand-alone mode. As a result, by the end of 1989 the library offered 21 CD-ROM databases on four public workstations. The Hitachi players purchased to support these databases proved to be incredible workhorses: they performed virtually without incident until the workstations themselves were replaced. One shudders to think about the amount of dust which must have settled in those machines.

Since the release of the West Report in $1998,{ }^{13}$ there has been extensive discussion in universities about pre-competitive cooperation and collaboration between libraries. Nowhere has this been more apparent than when Bond began to provide services to students and staff in 1989-90. Even before the university officially opened, library staff had to handle document requests for academic staff in preparation for teaching and to support their research. Prior to May 1989, all document requests were handled on our behalf by the Queensland University of Technology Library. The then Chief Librarian, Tom Cochrane, and his staff were extremely cooperative and helpful at this early stage in the library's development. In mid-1989 negotiations were undertaken with the University of Queensland so that Bond University Library could have access to the resources of the University of Queensland's libraries. Agreement was eventually reached to place a member of Bond staff at the University of Queensland to retrieve books, copy articles, etc. By the end of $1989,50 \%$ of document requests were being filled from UQ.

The University of Queensland also made available the QILL interlibrary loan management system in that same year. Developed under dBase IV, this software package enabled staff to improve turnaround times, performed housekeeping chores and recordkeeping, and provided statistical backup. Its interface with the Crosstalk software enabled Document Delivery staff to use the ILANET service for nearly all Australian transactions. And so from the very early days, the Document Delivery Unit was totally automated. The high pressure on that area is evidenced by the statistics for March to December 1989: 4285 document delivery requests were processed, of which 600 were for students and the remainder for staff.

The provision of reference services using a limited collection was a challenge for the subject specialists appointed to each of the Schools. Senior subject librarians had to cope with a very high demand for online database searches, e.g. DIALOG Ausinet, ranging from full retrospective literature searches for new teaching and research to quick searches of newspaper databases for students needing information on current issues. Because of the lack of many basic reference sources, no distinction was made between undergraduate and postgraduate requests.

In order to provide responses to the more complex reference queries, and to queries where the collection was found to be initially deficient, an agreement was reached with the Queensland University of Technology to provide reference services during the period 1989-90. This was phased out as the library gradually acquired more reference materials and access to specialised resources.

Access to the library's own bibliographic records, e.g. monographs and serials, was provided via HERMES, a PC-based library system developed by the Australian firm, TECHNIMARK. The OPAC machines ran in stand-alone mode until the whole system was replaced in early 1991 by A W A's SEA-URICA system (now marketed as Spydus Library Management System by Sanderson Computers).

\section{Full Circle}

In 1999 many of the underlying concepts proposed by Infour have become standard practice: ' ... networked information resources and services are now commonplace in the academic library' ${ }^{14}$ Today Bond University Library functions very much as do 
other smaller Australian tertiary libraries and faces most of the same challenges. Ten years later it is easy to lose sight of history; everything fades into the realm of myth. But to allow this to happen is to underrate the inherent value of the original model and its subsequent contribution.

Sandra Jeffries, inaugural Liaison Librarian for the School of Humanities and Social Sciences, perhaps best summed up the reasons for the 'failure' in 1989 to achieve the goal of a 'real electronic library':

The reasons for this are a complex mix of factors, the most important being: an unrealistic time-frame in which to integrate what was leadingedge technology before the university opened to students; a failure to differentiate between core and marginal projects; and a failure to convince the rest of the university community (particularly those with control of budgets) of the benefits of the electronic library concept. ${ }^{15}$

And yet in 1991 when most of us could only see what had not been achieved, she also wrote quite prophetically that 'the model that Bond was working towards is one of considerable value for an educational setting, and something that we will probably see as the norm in our working lives'. ${ }^{16}$

Hindsight reveals that at the very least the DUiE model gave us a basis on which to build subsequent services. It gave us an understanding of how to deliver information using a networked infrastructure. From the beginning, we did not look at the library as a defined physical locus, principally offering services which required the user to come to that location, but rather as one of a number of service providers (internal and external) whose resources patrons could access via networks.

Without the legacy of print (and tradition), we could easily adopt new technologies and new ways of doing things. For example:

- Extensive use of outsourcing for serials and cataloguing, which is much more prevalent now

- Integration of technical services, e.g. acquisitions rather than cataloguing staff downloading bibliographic records at the time of ordering collecting

- Extensive use of 'just-in-time' document supply rather than 'just-in-case'

- Extensive use of electronic materials as a primary source (rather than an 'add-on' to print materials) with the end result that materials are provided free of charge to the end-user regardless whether that person is a staff member, a postgraduate or an undergraduate student

- Early adoption of http, i.e. Mosaic, as our standard while other universities struggled with gopher.

The underlying vision of DUiE has become to a large extent a reality in the marketplace as the technology required to support it has developed. Ariel and the World Wide Web, for example, can be seen as technological developments which substantially validate the DUiE model. As a document transmission system, Ariel integrates many of the scanning, sending and receiving functions of the workstation proposed by Infour. Interestingly, the copyright regulations which were an impediment to the storage of high use materials outlined by Infour in 1989 are still in place today. The Web, for its part, provides document query and delivery on an even larger scale than envisaged perhaps by the US consultants. Although their prediction of local mass optical storage has been supplanted by web-based vendors' large full-text 
databases, the Web has helped to create the 'user workstation' which was an integral component of the consultants' prototype.

\section{Notes}

${ }^{1}$ A Bond 'A Message from the Founder and Patron' in E Brownrigg Strategic Planning for Computing, Information and Technology at Bond University Gold Coast Office of Computing and Information Technology Bond University 1988 p33

${ }^{2} \mathrm{C}$ Tweedie 'Building a New University Library in the Information Age' Australian Library Review vol 7 no 11990 pp21-26

${ }^{3}$ P Battin 'The Electronic Library' Collection Management vol9 1987 pp133-41

${ }^{4}$ E Brownrigg Strategic Planning for Computing ...

5 B Butler R Goodram 'Designing the Electronic Library: A Functional Model' Australian Library Review vol 7 no 11990 ppl5-19

${ }^{6}$ ibid

7 ibid

8 R J Goodram B B Butler 'Why Electronic Libraries? Today's Problems' in Communicating in the Information Age Melbourne Victorian Association for Library Automation 5th Biennial Conference November 13-15 1989 ppl4-20

${ }^{9}$ Richardson 'Integration of Campus-Wide Services in North American Universities Through Communication Technology' 2 vol Unpublished report for Victorian Association for Library Automation 1991

${ }^{10} \mathrm{E}$ Woodberry 'Issues in the Establishment of a New Serials Collection' Serials Publishing and Acquisitions in Australia vol 4 no 21993 pp69-76

${ }^{11}$ E Woodberry 'Serials Management in a Private University' Serials Management in Australia and New Zealandvol3 no 3/4 1993 ppl9-25

${ }^{12} \mathrm{P}$ Wear 'University in Bondage' The Bulletin 1 August 1995 pp36-37; M Drummond 'Bond Uni Deal Frees Land for Sale' Australian Financial Review 16 August 1999 p34

${ }^{13}$ Australia Higher Education Financing and Policy Review Committee Learning for Life: Final Report: Review of Higher Education Financing and Policy Canberra AGPS 1998

${ }^{14} \mathrm{H}$ Bruce P Clayton 'An Internet Role for the Academic Librarian?' Australian Academic \& Research Libraries vol30 no 31999 ppl71-187

${ }^{15} \mathrm{~S}$ Jeffries 'Information Services at Bond University: The Search for the Electronic Library' Unpublished paper presented at Subject Librarians Conference UNISA July 11-12 1991

16 ibid 